\title{
Research on Effects of Incorporation of Milk Vetch (Astragalus Sinicus) on Paddy Soil Microbes
}

\author{
Xu Wei \\ Hainan University, Haikou, Hainan, China, 570228 \\ hunter2011@foxmail.com
}

Keywords: Milk vetch, Astragalus sinicus, Soil microbial populations, Soil microbes.

\begin{abstract}
Objectives Chinese milk vetch (Astragalus sinicus) is a major green manure planting in southern paddy fields. This paper designs an experimental to discuss the effects of incorporation of milk vetch on paddy soil microbes, including theeffects on microbial population, the effects on microbial biomass carbon, the effects on microbial biomass nitrogen and the effects on microbial biomass phosphorus in order to provide some references for the relevant researchers.
\end{abstract}

\section{Concept of Chinese Milk Vech}

The Chinese milk vetch, also known as Astragalus sinicus, is native to China. It likes warm and humid conditions and has a certain hardy ability. The Chinese milk vetchrequires sufficient moistureduring the whole growth period. Milk vetch on the soil loose, Sandy and clayey loam is suitable to. The Chinese milk vetch has low tolerance to salt tolerance, which is a kind of legumes and astragalus. A mast root, lateral roots buried shallow, a cylindrical stem, hollow, tender and juicy, sparsely pubescent. Leaves mostly odd pinnate, flowers in umbels, axillary, few top students, pod two column joint into a triangle, kidney shaped seed, seed coat smooth, root and seed and straw can be used as medicine, replenishing qi to invigorate the spleen, detoxification analgesic effect. China is one of the main honey plants. Chinese milk vetch belong to the legume Astragalus is a traditional green manure crop and paddy rice the main winter green manure crop it can improved soil, improve soil fertility, to increase the yield of rice and maintain the sustainable development of rice production has important significance. Chinese milk vetch, as a kind of main paddy leguminous green manure contains rich trace elements and its pressure field can be fixed, activation and enrichment in soil nutrients for crop growth, increase the content of soil organic matter, improve the ecological environment. Moreover, in the "rice-rice-milk vetch"rotation, it reduces plant diseases and insect pests, improves soil micro environment.

\section{Design and Methods of the Experiment}

The experiment is set in Liu village in Dingxi County in Loess Plateau hilly and gully area. The area belongs to temperate semiarid areas, with an average altitude of $2000 \mathrm{~m}$, with an average annual solar radiation $141.6 \mathrm{kcal} / \mathrm{cm} 2$, sunshine time $2476.6 \mathrm{~h}$, with an average annual temperature of 6.4 degrees, is more than or equal to 0 DEG C temperature 2933.5 DEG C, is equal to or more than 10 DEG $C$ temperature 2239.1 DEG C; no frost 140d. For many years, the average precipitation $390.9 \mathrm{~mm}$, the annual evaporation rate was 1531 , the dryness degree was 2.53 , the $80 \%$ guaranteed rate was $365 \mathrm{~mm}$, and the variation coefficient was $24.3 \%$, which is the typical rain fed agricultural region. The soil is yellow cotton soil, typical soft soil, deep soil, uniform texture, good water storage performance. The trial began in August 2001, and there were 6 treatments, 4 times repeat, $4 \mathrm{~m} * 20 \mathrm{~m}$, and the random order. Implementation of spring wheat and pea double sequence 
rotation system, spring wheat processing nitrogen fertilizer hm2 105kg/; pure hm2 $\mathrm{P}_{2} \mathrm{O}_{5} 105 \mathrm{~kg} /$. We use the nitrogen fertilizer $20 \mathrm{~kg} / \mathrm{hm} 2$, pure $\mathrm{hm} 2 \mathrm{P}_{2} \mathrm{O}_{5} 105 \mathrm{~kg} / \mathrm{hm} 2$.

Soil microbial population was determined by sampling date of March 15, 2014. Determination of soil microbial biomass carbon, nitrogen and phosphorus sampling dates for before planting (15 April, 2015), post-harvest (August 6, 2014), and freeze before (January 5, 2015). Beef extract peptone medium to cultivate bacteria. We use with Gause's enrichment medium to cultivate the fungi and use Beck medium to cultivate actinomycetes.

Table 1 Extractant and Formula of Soil Microbial Biomass

\begin{tabular}{|l|c|c|l|}
\hline Identification Indexes & Extractant & Soil/Liquid & Formula \\
\hline Microbial Biomass C & $0.5 \mathrm{~mol} / \mathrm{L} \mathrm{K}_{2} \mathrm{SO}_{4}$ & $1: 4$ & $\mathrm{E}_{\mathrm{C}} / \mathrm{K}_{\mathrm{EC}}$ \\
\hline Microbial Biomass N & $0.5 \mathrm{~mol} / \mathrm{L} \mathrm{K}_{2} \mathrm{SO}_{4}$ & $1: 4$ & $\mathrm{E}_{\mathrm{N}} / \mathrm{K}_{\mathrm{EN}}$ \\
\hline Microbial Biomass P & $0.5 \mathrm{~mol} / \mathrm{L} \mathrm{K}_{2} \mathrm{SO}_{4}$ & $1: 4$ & $\mathrm{E}_{\mathrm{P}} / \mathrm{K}_{\mathrm{EP}}$ \\
\hline
\end{tabular}

\section{Effects of Incorporation of Milk Vetch on Paddy Soil Microbes}

Effects on Microbial Population. The effects of different fertilization treatments on soil microbial populations were shown in table 2 . The bacteria were the most in the soil, followed by actinomycetes and fungi.

Talbe 2 Effects of Milk Vectch and Fertilizer on Microbial Population

\begin{tabular}{|c|c|c|c|}
\hline \multirow{2}{*}{ Index } & \multicolumn{3}{|c|}{ CFU. $^{-1}$} \\
\cline { 2 - 4 } & aerobic bacteria & fungi & actinomycetes \\
\cline { 2 - 4 } & $\left({ }^{*} 10^{6}\right)$ & $\left(* 10^{4}\right)$ & $\left({ }^{*} 10^{6}\right)$ \\
\hline CK & $2.41 \mathrm{e}$ & $1.51 \mathrm{~d}$ & $2.01 \mathrm{~d}$ \\
\hline $\mathrm{T} 1$ & $4.06 \mathrm{~d}$ & $2.85 \mathrm{c}$ & $2.25 \mathrm{c}$ \\
\hline $\mathrm{T} 2$ & $8.21 \mathrm{~b}$ & $3.15 \mathrm{~b}$ & $2.74 \mathrm{~b}$ \\
\hline T3 & $8.95 \mathrm{a}$ & $3.83 \mathrm{a}$ & $3.12 \mathrm{a}$ \\
\hline T4 & $6.07 \mathrm{c}$ & $3.31 \mathrm{~b}$ & $2.88 \mathrm{~b}$ \\
\hline
\end{tabular}

Data Source: Effects of Astragalus sinicus manure and fertilizer combined application on soil nutrient and microbiological characteristics

Microbial Population were greatly increased in the flowering stage of milk vetch, but declined in the rice harvest period. This may be due to the bacterial growth to provide better growing environment.Compared to the Chinese milk vetch by the growth of green manure, ryegrass biomass larger root exudates, so they can better promote bacterial growth. Single cropping rice harvest period, Chinese milk vetch and rye grass with the population of soil bacteria was higher than that of the control treatment was higher than that of single species with Chinese milk vetch, indicating that the clover ryegrass mixture sowing after returning the green manure can better promote bacterial growth. The population of actinomycetes in soil increased firstly and then decreased. Milk vetch flowering, processing and application of chemical fertilizer treatment reached the maximum control, the situation in Jiangxi and similar test. The early rice harvest period, Chinese milk vetch and milk vetch with chemical fertilizer treatment reached the highest population of actinomycetes. Processing and planting Chinesemilkvetch compared with CK treatment, the population of actinomycetes were lower than that of the latter in each period. Single application of fertilizer and Chinese milk vetch and fertilizer treatments compared both in the soil at milk vetch seedling and flowering put little difference in actinomycetes population, but with the seasonal variation in the gap between the two is gradually increasing. The population of soil fungi showed a trend of first increase and then decrease. Overall, the population of soil fungi was smaller with the population of soil fungi; milk 
vetch treatment was significantly higher than that of control. This shows that in no fertilizer condition, planting turnover of Astragalus sinicus can improve soil fungi quantity. Single application of fertilizer treatment and the milk vetch plus chemical fertilizer quantity of soil fungi in the milk vetch flowering has greatly increased, it declined markedly in the period of late rice harvest, except for seedling of Chinese milk vetch, other period both the population of fungi in the soil were higher than control treatment. Compared with both of them, Chinese milk vetch and fertilizer treatment the population of fungi in the soil than in chemical fertilizer treatment.

Effects on Microbial Biomass Carbon. The factors of Astragalus sinicus on microbial biomass carbon is as follows: the fifty percent soil incorporation effect significantly, a significant effect; depth of all, Chinese milk vetch have extremely significant effects, incorporation effect is not significant; surface layer and subsurface incorporation milk vetch interaction effects were not significant. Factors effect test points out that the differences in the effects of milk vetch density of the surface soil microbial biomass carbon reached extremely significant level, fifty percent soil microbial biomass carbon 30\% milk vetch $16.8 \%$ higher than the N50\% milk vetch than high 50\% milk vetch $12.6 \%$, 90\% milk vetch than high $70 \%$ milk vetch $15.4 \%$, no incorporation plowing soil microbial biomass carbon increased by an average of $14.9 \%$ than that of the conventional. No incorporation can improve the surface layer of the soil microbial biomass carbon is due mainly to heterotrophic populations of soil microorganisms and the process of life activity requires a certain amount of energy consumption, no incorporation without disturbing the earth layer, plant residues mainly accumulated in soil, accordingly can for microbial life sustaining activities sufficient energy; and continuous no incorporation in the topsoil becomes shallow, plant roots were concentrated in the surface layer of the soil, root stubble and a large population of low molecular weight of root exudates also aggravate the soil microbial reproduction, the exuberant life activities. But in incorporation treatment, plant residues and application of fertilizer is with mechanical incorporation and evenly distribution in $0-20 \mathrm{~cm}$ incorporation layer, due to the dilution effect of the fifty percent soil organic carbon content than no incorporation and low, resulting in the soil in the soil microbial biomass carbon than the incorporation low. Chinese milk vetch density of subsurface soil microbial biomass carbon was not significantly affected. Soil microbial biomass carbon is $30 \%$ milk vetch> no milk vetch, $90 \%$ milk vetch $>70 \%$ milk vetch, but N50\% milk vetch $<50 \%$ milk vetch. This may resulted by the soil temperature and microbial carbon source, yet to be further verified.

Effects on Microbial Biomass Nitrogen. Although differences in the effects of Chinese milk vetch density on soil microbial biomass nitrogen was not significant, but no incorporation could improve the surface layer of the soil microbial biomass nitrogen. Fifty percent soil microbial biomass $\mathrm{N}$ was higher than that of no milk vetch $7.8 \%$, and N50\% milk vetch was higher than $50 \%$ milk vetch $10.9 \%$. However, the soil microbial biomass nitrogen $30 \%$ milk vetch $>$ no milk vetch, $90 \%$ milk vetch $<70 \%$ milk vetch, $90 \%$ milk vetch $<70 \%$ milk vetch, fifty percent, and all, were further studied. Analysis of variance showed that Chinese milk vetch on the surface layer of soil microbial biomass nitrogen difference significantly. Fifty percent soil, average N50\% milk vetch than $30 \%$ milk vetch high $18.9 \%$ 50\% milk vetch t $15.6 \%$ higher than, namely Chinese milk vetch straw than not milk vetch on soil microbial biomass nitrogen increased by an average of $17.3 \%$; of fifty percent $90 \%$ milk vetch than $30 \%$ milk vetch high $6.3 \%, 70 \%$ milk vetch than $\mathrm{t}$ high $19.4 \%$. That table layer film of Chinese milk vetch than Chinese milk vetch increased by an average of $12.9 \%$. Multiple comparisons showed that the $0-5 \mathrm{~cm}$ soil layer, soil microbial biomass nitrogen mean order: $\mathrm{N} 50 \%$ milk vetch $>70 \%$ milk vetch $>90 \%$ milk vetch $>30 \%$ milk vetch $>\mathrm{T}$, significant difference were Chinese milk vetch than Chinese milk vetch. Due to the surface soil layer under the condition of Chinese milk vetch, higher soil moisture, soil moisture content may have great 
influence on the soil microbial biomass nitrogen. It has been found that soil moisture is closely related to the microbial biomass, and soil microbial biomass increases with the increase of water content in a certain range. Chinese milk vetch could enhance the soil water holding capacity, soil in the alternation of drying and wetting is easing, and thus more conducive to the soil microbial life activities. At the same time, but also can prevent milk vetch soil nitrogen volatilization while the effective nitrogen is higher in soil. In addition Astragalus sinicus straw will add more organic matter and for soil microbes provide sufficient carbon and energy source, $\mathrm{C} / \mathrm{N}$ ratio increased, increased the quantity of microorganisms in the soil at the same time also increased the nitrogen fixing ability, and soil microbial biomass nitrogen increased. 50\% milk vetch is $19.8 \%$ higher than $\mathrm{T}, 70 \%$ milk vetch is higher thanno milk vetch $23.3 \%$. And N50\% milk vetch, $90 \%$ milk vetch and $30 \%$ milk vetch is not much difference. Soil microbial biomass N: $70 \%$ milk vetch $>50 \%$ milk vetch $>\mathrm{N} 50 \%$ milk vetch $>30 \%$ milk vetch $>90 \%$ milk vetch. The soil microbial biomass nitrogen was the highest in this layer, and N50\% milk vetch could significantly reduce the soil temperature of observation layer, and 50\% milk vetch and 30\% milk vetch could improve the soil temperature at $15 \mathrm{~cm}$ level, and $90 \%$ milk vetch and $70 \%$ milk vetch could prevent the soil temperature from falling at night ".

Effects on Microbial Biomass Phosphorus. The dynamic changes of soil microbial biomass $\mathrm{P}$ was the highest in August, November, and the lowest in March. No milk vetchwas the lowest in August and the change of the change was different from the other. The reason for this was to be further verified. After the fall of the surface of the straw, the soil was gradually entered into the soil by the animal disturbance. Soil microorganisms have access to adequate energy supply, andcontinue to proliferate. In winter, the temperature is low, and the metabolism is weak, the microorganism can survive in the lower energy supply, so that the soil can maintain higher microbial biomass phosphorus. As the weather warms, microbial activity increases, and the energy of the soil is quickly depleted. When the energy supply is insufficient, microbial activity begins to weaken, and the biomass decreases, and the trend is not reversed until the soil has been supplied with foreign energy. The effect of sub surface layer was very significant. The effects of various factors, the difference of fifty percent soil effects were not significant, but the effect is greater than the incorporation effect of Astragalus sinicus. All profile of milk vetch effect is not significant, differences in farming and incorporation significantly interaction effect of Astragalus sinicus. In addition milk vetch was higher than that of non-Chinese milk vetch, due to the films of Astragalus sinicus L. the role of insulation, surface layer of soil microbial biomass phosphorus may be affected by temperature. From the following figures can illustrate this, $0-5 \mathrm{~cm}$ soil, straw, Chinese milk vetch on soil microbial biomass $\mathrm{P}$ average N50\% milk vetch $30 \%$ milk vetch $4.9 \%$ higher than that of 50\% milk vetch t $34.4 \%$ higher than; $70 \%$ milk vetch Astragalus sinicus films than $\mathrm{t}$ high $14.1 \%$, 90\% milk vetch and 30\% milk vetch had little difference, but $90 \%$ milk vetch $>30 \%$ milk vetch; all soil layer, soil microbial biomass $\mathrm{P}$ mean order: $90 \%$ milk vetch $>50 \%$ milk vetch $>30 \%$ milk vetch $>70 \%$ milk vetch, $90 \%$ milk vetch $70 \%$ milk vetch had significant difference between, remaining differences not significant. $90 \%$ milk vetch is higher than $30 \%$ milk vetch $22.4 \%$, soil microbial biomass phosphorus may be related to temperature, but $70 \%$ milk vetch is less than $50 \%$ milk vetch. The reasons are for further study. Although the density of Chinese milk vetch on soil microbial biomass phosphorus was not significantly affected, but fifty percent soil microbial biomass phosphorus is $25.6 \%$ higher than $30 \%$ milk vetch. $90 \%$ milk vetch and $70 \%$ milk vetch is $11 \%$ higher than all parts of soil milk vetch. Soil microbial biomass $\mathrm{P}$ of $90 \%$ milk vetch is $49.1 \%$ higher than that of $70 \%$ milk vetch. 


\section{References}

[1] S.X. Wan, H.B. Zhu, S. Tang, X.S. Guo, Y.Q. Wang, Effects of Astragalus sinicus manure and fertilizer combined application on soil nutrient and microbiological characteristics, Soil and Fertilizer Sciences in China, 3(2015)79-83.

[2] J.T. Zhang, W.D. Cao, C.X. Xu, J. Liu, Effects of incorporation of milk vetch (Astragalus sinicus) on microbial populations and enzyme activities of paddysoil in Jiangxi, Soil and Fertilizer Sciences in China, 1(2012)19-25.

[3] J.T. Zhang, Effectsof IncorporationofMilkVetch (Astragalus sinicus) on FertilityCharactersofPaddy Soil inSouthChina, Chinese Academy of Agricultural Sciences, 2011.

[4] Z.L. Yan, Y. Fang, J.C. Chen, F. Wang, C.M. He, X.J. Lin, Effect of turning over Chinese milk vetch (Astragalus sinicus L.) on soil nutrients and microbial properties in paddy fields, Journal of Plant Nutrition and Fertilizer, 5(2014)1151-1160. 